\title{
Carrier Effects on the Chemical and Physical Properties of Freeze-Dried Encapsulated Mulberry Leaf Extract Powder
}

\author{
William Tchabo, ${ }^{1}$ Yongkun Ma, ${ }^{*, 1}$ Giscard Kuate Kaptso, ${ }^{2}$ Emmanuel Kwaw, ${ }^{1}$ Rosine \\ Wafo Cheno, ${ }^{3}$ Meng Wu, ${ }^{1}$ Richard Osae, ${ }^{1}$ Shengmei $\mathrm{Ma}^{1}$ \\ and Muhammad Farooq ${ }^{1}$
}

\author{
${ }^{1}$ School of Food and Biological Engineering, Jiangsu University, 301 Xuefu Road, Zhenjiang 212013, P.R. China. \\ ${ }^{2}$ Department of Social Economy and Family Management, Higher Technical Teacher's Training College (HTTTC), \\ University of Buea, P.O Box 249 Buea Road, Kumba, Cameroon \\ ${ }^{3}$ Department of Health Policy and Management, Jiangsu University, 301 Xuefu Road, Zhenjiang 212013, P.R. China. \\ *Corresponding author: E-mail: mayongkun@ujs.edu.cn
}

Received: 20-04-2018

\begin{abstract}
In this study mulberry leaf extract biocompounds were encapsulated with sodium carboxymethyl cellulose $(0.55 \%$, $0.70 \%$, and $0.75 \% \mathrm{w} / \mathrm{v})$ or maltodextrin $(8 \%, 10 \%$, and $12 \% \mathrm{w} / \mathrm{v})$. The outcome of this work demonstrated that maltodextrin showed the highest encapsulation efficiency towards the phenolic acids and 1-deoxynojirimycinin whereas the flavonols and gamma-aminobutyric acid were best encapsulated by sodium carboxymethyl cellulose. Moreover, the antioxidant properties of the encapsulated powders were found to be associated with their nutraceutical constituents. In addition, the powders produced with sodium carboxymethyl cellulose were typified by suitable hygroscopicity, wettability time, glass transition temperature, and bulk properties than those obtained with maltodextrin which was characterized by desirable porosity, water solubility, moisture content, water activity, color, particle, and flowability properties.
\end{abstract}

Keywords: Freeze drying, mulberry leaf; encapsulation; sodium carboxymethyl cellulose; maltodextrin

\section{Introduction}

Morus plant species possess enormous importance in economic, industrial, and domestic fields. ${ }^{1}$ In Asia the plant is grown chiefly for their leaves as food for silkworms (Bombyx mori L.). ${ }^{2}$ With the development of sericulture production and advancement in biotechnology, new mulberry varieties are increasingly in demand. However, a huge amount of the leaves are wasted by the end of the silk production cycle. ${ }^{2}$ Recent studies have highlighted the health benefits of the leaf in the treatment of human ailments. ${ }^{3,4}$ Nevertheless, the leaf is mostly harvested seasonally, thus making it hard to be utilized by the food and nutraceutical industries, because of their delicate structure, susceptibility to spoilage and low stability in storage. Hence, considering, the fragile nature of the leaves and the large quantities lost during postharvest handling, mulber- ry leaf could be processed into powder to increase its economic value.

The potential industrial application of mulberry leaf powder as a functional ingredient for the food and pharmaceutical industries as an alternative solution for its post-harvest conservation of mulberry leaf is limited due to its high perishability and postharvest handling costs (storage, packing, and transport). Moreover, the high content of nutraceuticals in mulberry leaf makes its powder less soluble in water and unstable during processing, therefore leading to technical hitches in its industrial utilization, ${ }^{5}$ In addition, bioactive compounds are highly susceptible to degradation when exposed to environmental conditions thus, reducing their bioavailability. ${ }^{6}$ In this sense, production of an encapsulated powder from mulberry leaf extract might be an alternative to reduce the technical difficulties in its industrial application and ensure product availability. 
From a food engineering perspective, encapsulation is an effectual process frequently employed in the pharmaceutical and food industries to preserve the functionality of biomolecules by entrapping the active agents in wall materials. ${ }^{7}$ Encapsulation of plant extract enhance the final product quality and process capability, low-cost delivery, easy maintenance, and protect active compounds against physical and chemical stress. ${ }^{8}$

Encapsulation using freeze drying is a suitable process employed to improve the stability of thermosensitive biocompounds while preserving their biological activities. ${ }^{9}$ Several encapsulating agents such as carbohydrates, cellulose derivatives, and gums have been applied in freeze drying owing to their low viscosity and high solubility. ${ }^{10}$ However, each wall material has advantages and drawbacks in terms of their characteristics, which influence the properties of the encapsulated powder. ${ }^{11}$

In the last decade, encapsulation of herbal extract has been investigated by numerous scientists and it has been established that entrapment efficiency of biocompounds depends on the encapsulation conditions, such as the type and concentration of the wall material. ${ }^{12}$ As reported by $\mathrm{Da}$ Rosa et al., ${ }^{13}$ the type of encapsulating agent is a key determinant of the functional properties of an encapsulated microparticle. Moreover, the polarity, molar mass, and functionality of the carrier significantly influence the chemical stability, solubility, physical state, and entrapment of nutraceutical compounds. ${ }^{14}$ Individual nutraceutical components from different groups differ in structure, properties and may have different encapsulation trends during freeze-drying. ${ }^{15}$ However, most research conducted in literature focus on the entrapment efficiency of the total polyphenol content. Howbeit, these scientific contributions are pertinent but, none of them utterly covers the encapsulation efficiency of individual nutraceuticals of the herbal extracts. Despite, numerous scientific reports on encapsulation of herbal extracts, there is still scarcity of knowledge on the impact of carrier materials on entrapment efficiency of individual nutraceutical compounds in the herbal extracts and the physical characteristics of encapsulated extract powder.-

To the best of our knowledge, there are limited studies on mulberry leaf extract encapsulation. Hence, the present investigation sought to assess the effects of encapsulating materials (sodium carboxymethyl cellulose and maltodextrin) and fractions of carrier materials to core ratio on the chemical (individual nutraceuticals retention, encapsulation efficiency, and antioxidant) and physical (particle, packing, reconstitution, shelf-life, and chromatic) characteristics of encapsulated mulberry leaf extract powder. The scientific contribution of this investigation was to valorize mulberry leaf by the development of a powder with nutraceutical value, while the technological application of encapsulating mulberry leaf extract was to preserve the physical characteristics of the powder that define its behavior during processing, storage, and handling to ensure its industrial utilization.

\section{Materials and Methods}

\section{1. Materials}

Mulberry leaf (Morus alba) was acquired from Zhenjiang mulberry variety nursery base (Jiangsu, China). Maltodextrin 13-17DE (MD, 1200 DA), sodium carboxymethyl cellulose (CMC, $\sim 90000 \mathrm{DA}$ ), nutraceutical standards, and other reagents of AnalaR grade were obtained from Sigma-Aldrich (St. Louis, USA).

\section{2. Experimental Methodology}

\section{2. 1. Nutraceuticals Extraction}

The extraction of nutraceutical compounds was conducted following the methodology described by Tchabo et al. ${ }^{16}$ using a two-step extraction. Concisely, the fresh leaf was lyophilized $\left(48 \mathrm{~h},-60{ }^{\circ} \mathrm{C}, 0.02 \mathrm{mbar}, \mathrm{FD}-1 \mathrm{~A}-50\right.$, Boyikang Laboratory Instruments, Beijing, China) and powdered using a jet miller (0101S Jet-O-Mizer Milling, Fluid Energy Processing and Equipment Company, Telford, USA). Subsequently, $10 \mathrm{~g}$ of the powder (500 mesh) was added to warm distilled water $\left(70{ }^{\circ} \mathrm{C}, 400 \mathrm{ml}\right)$ and stirred for $40 \mathrm{~min}$ at $300 \mathrm{rpm}$ using a rotary water bath (isothermal shaker DK-600B, Jianqiao Testing Equipment, Guangdong, China). Afterward, the mixture was centrifuged (15 $\min / 6000 \mathrm{~g} / 4^{\circ} \mathrm{C}$, Beckman Avanti J-26 XP Coulter, Fullerton, California, USA), and filtered (whatman \#1 paper). Then, the nutraceutical extract (NE) was kept at $4^{\circ} \mathrm{C}$ in an amber flask prior to encapsulation.

\section{2. 2. Nutraceutical Extract Encapsulation}

The addition rate of encapsulating agents was chosen based on trials with respect to the feed mixture stability, processing cost, and encapsulated powders quality (unpublished data). Concisely, the NE and different ratio of $\mathrm{CMC}(0.55 \%, 0.70 \%$, and $0.75 \% \mathrm{w} / \mathrm{v})$ or $\mathrm{MD}(8 \%, 10 \%$, and $12 \% \mathrm{w} / \mathrm{v}$ ) were homogenized (Ika-Ultra-Turrax T25, China) at $25^{\circ} \mathrm{C}$ for $5 \mathrm{~min}$ at $12000 \mathrm{~g}$. The feed mixtures were then poured into a petri dish $(1 \mathrm{~cm}$ depth), frozen at $-29{ }^{\circ} \mathrm{C}$ for $24 \mathrm{~h}$, and lyophilized (FD-1A-50, Boyikang Laboratory Instruments, Beijing, China) for $72 \mathrm{~h}(0.02$ mbar, $\left.-60{ }^{\circ} \mathrm{C}\right)$. Afterwards, the freeze-dried cake was powdered $(50 \mathrm{~g} / 10 \mathrm{~s} / 40 \mathrm{rpm})$ with a laboratory blender Mixomat mini (Fuchs Maschinen AG, Switzerland) and the encapsulated nutraceuticals powder (ENP) was stored (at $25^{\circ} \mathrm{C}$ ) in a vacuum sealed aluminum bag and kept in a desiccator containing silica gel prior to assay (within 2 weeks).

\section{3. Nutraceuticals Assay}

The free nutraceuticals supernatant (non-encapsulated) and the total supernatant (within and outside the microparticles) were obtained as reported by Akbas et al. ${ }^{17}$ Briefly, for the free nutraceuticals supernatant, the ENP 
(500 mg) was dissolved in an ethanol and methanol mixture $(1: 10,50 \mathrm{ml})$. For the total supernatant, the ENP (500 $\mathrm{mg}$ ) was added to an ethanol, acetic acid and distilled water mixture $(50: 8: 42, \mathrm{v} / \mathrm{v}, 50 \mathrm{ml})$. The mixtures were stirred (10 s) and centrifuged $\left(9056 \mathrm{~g} / 5 \mathrm{~min} / 4{ }^{\circ} \mathrm{C}\right)$. The supernatants were used to assay the contents of nutraceutical compounds. The contents were expressed as milligram per gram of sample on a dry basis.

Nutraceuticals assays were carried out according to Tchabo et al. ${ }^{16}$ using an HPLC system (Shimadzu Corporation, Kyoto, Japan) constituted of a SCL-10A system controller, LC-20AB pump, DGU-20A5R degasser, SIL 20AC autosampler, CTO-20AC column oven, SPD-M20A photodiode array detector coupled with a ZORBAX-SB C18 $(250 \mathrm{~mm} \times 4.6 \mathrm{~mm}, 5-\mu \mathrm{m})$ column (Agilent, Santa Clara, USA).

\section{3. 1. Phenolics}

Chlorogenic acid (CHA), caffeic acid (CA), kaempferol-7-O-glucoside (K7G), quercetin-3-rutinose (Q3R), quercetin-3-O-glucoside (Q3G), kaempferol 3-(6-rhamnosylglucoside) (K3R), quercetin 3-(6-malonylglucoside) (Q3M), kaempferol-3-glucoside (K3G) and kaempferol 3-(6-malonylglucoside) (K3M) were measured as described by Tchabo et al. ${ }^{16}$ Concisely, the supernatant (10 $\mu \mathrm{l})$ was eluted $\left(60 \mathrm{~min}, 1 \mathrm{ml} / \mathrm{min}, 40^{\circ} \mathrm{C}\right)$ with a mobile phase of acetonitrile and $0.1 \%$ formic acid (20:80). The data was recorded at $280 \mathrm{~nm}$ for phenolic acids and 370 $\mathrm{nm}$ for flavonols.

\section{3. 2. 1-deoxynojirimycin}

1-deoxynojirimycin (DNJ) was measured as described by Tchabo et al. ${ }^{16}$ Concisely, the supernatant (500 $\mu \mathrm{l})$ was mixed with potassium borate buffer $(0.4 \mathrm{M}, \mathrm{pH}$ $8.5,50 \mu \mathrm{l})$ and 9-fluorenylmethyl chloroformate $(5 \mathrm{mM}$ in acetonitrile, $100 \mu \mathrm{l})$. The mixture was held at $20^{\circ} \mathrm{C}$ for 20 min after which glycine $(50 \mu \mathrm{l})$ and acetic acid $(17.5 \mathrm{mM}$, $4.3 \mathrm{ml}$ ) were added. Then, $10 \mu \mathrm{l}$ of the mixture was eluted (30 $\mathrm{min}, 1 \mathrm{ml} / \mathrm{min}, 25^{\circ} \mathrm{C}$ ) with a mobile phase of acetonitrile and $0.1 \%$ acetic acid (50:50). The data was recorded at $254 \mathrm{~nm}$.

\section{3. 3. Gamma-aminobutyric Acid}

Gamma-aminobutyric acid (GABA) was measured as described by Tchabo et al. ${ }^{16}$ Concisely, the supernatant $(400 \mu \mathrm{l})$ was mixed with potassium borate buffer $(0.5 \mathrm{M}$, $\mathrm{pH}$ 8.5, $100 \mu \mathrm{l})$ and 9-fluorenylmethyl chloroformate (3 $\mathrm{mM}$ in acetonitrile, $500 \mu \mathrm{l})$. The mixture was held at $25^{\circ} \mathrm{C}$ for $10 \mathrm{~min}$ after which acetic acid $(1 \mathrm{M}, 100 \mu \mathrm{l})$ was added. Then, $20 \mu \mathrm{l}$ of the mixture was eluted $\left(0.5 \mathrm{ml} / \mathrm{min}, 40^{\circ} \mathrm{C}\right)$ with a mobile phase constituted of eluent (A) sodium acetate buffer (0.1 M, pH 5.8, 0.05\% triethylamine) and eluent (B) acetonitrile $(80 \%)$. The gradient was as follows: 20 -
50\% B (0-5 min), $50-100 \%$ B (5-10 min), 100\% B (10-20 $\mathrm{min}), 100-20 \% \mathrm{~B}(20-25 \mathrm{~min})$ and $20 \% \mathrm{~B}(25-35 \mathrm{~min})$. The data was recorded at $262 \mathrm{~nm}$.

\section{3. 4. Nutraceutical Retention}

Nutraceutical retention (NR) was assessed according to $\mathrm{Du}$ et al..$^{18}$ as the ratio between the total content of each nutraceutical compound present in the ENP to that present in the NE. The NR was calculated as follows:

$$
\begin{aligned}
& \% N R=\left(\left(\text { total content of } E N P^{\star} 100\right)\right) \\
& (\text { total content }) \text { of } N E
\end{aligned}
$$

\section{3. 5. Encapsulation Efficiency}

Encapsulation efficiency (EE) was determined according to Akbas et al. ${ }^{17}$ as the difference between the total content and the free content of each nutraceutical compound. The EE was calculated as follows:

$$
\begin{aligned}
& \% E E=((\text { total content-free content })) \\
& (\text { total content }) \times 100
\end{aligned}
$$

\section{4. Antioxidants Assay}

The antioxidant assays were performed according to Tchabo et al. ${ }^{16}$ using the total supernatant. The cupric ion reducing capacity (CUPRAC), 2,2-azino-bis-(3-ethylbenzothiazoline-6-sulfonic acid) (ABTS), 1,1-diphenyl-2-picrylhydrazyl (DPPH) and ferric reducing antioxidant power capacity (FRAP) were expressed as $\mathrm{mM}$ of Trolox equivalent per gram of sample on dry basis.

\subsubsection{ABTS}

The supernatant $(125 \mu \mathrm{l})$ was mixed with $5 \mathrm{ml}$ of ABTS solution which was constituted of $2.45 \mathrm{mM}$ ABTS in ammonium persulfate (incubated in darkness for 16 hours). The mixture was held for $15 \mathrm{~min}$ at $25^{\circ} \mathrm{C}$ and the absorbance read at $734 \mathrm{~nm}$.

\section{4. 2. CUPRAC}

The supernatant $(100 \mu \mathrm{l})$ was mixed with $4 \mathrm{ml}$ of a solution which was constituted of neocuproine $(7.5 \mathrm{mM})$, copper(II) chloride $(10 \mathrm{mM})$, ammonium acetate (1M) and distilled water (1:1:1:1). The mixture was held for 60 min at $25^{\circ} \mathrm{C}$ and the absorbance read at $450 \mathrm{~nm}$.

\section{4. 3. DPPH}

The supernatant $(1 \mathrm{ml})$ was mixed with $6 \mathrm{ml}$ of DPPH solution $(60 \mathrm{mM}$ in methanol). The mixture was held for $30 \mathrm{~min}$ at $25^{\circ} \mathrm{C}$ (in darkness) and the absorbance read at $517 \mathrm{~nm}$. 


\section{4. 4. FRAP}

The supernatant $(200 \mu \mathrm{l})$ was mixed with $6 \mathrm{ml}$ of a solution which was constituted of acetate buffer $(300 \mathrm{mM}$, $\mathrm{pH} 3.6)$, iron(III) chloride (20 mM), TPTZ (10 mM in 40 $\mathrm{mM} \mathrm{HCl})(1: 10: 1)$ and distilled water $(600 \mu \mathrm{l})$. The mixture was held for $30 \mathrm{~min}$ at $37^{\circ} \mathrm{C}$ and the absorbance read at $593 \mathrm{~nm}$.

\section{5. Particle Properties}

Particle size (PS) and particle density (PD) were measured according to Santhalakshmy et al. ${ }^{19}$

PS of the ENP was measured using a Master-Sizer 3000 (Malvern Instrument Ltd, Worcestershire, UK) and expressed as geometric mean $\left(d_{50}\right)$. For the determination of the PD, the ENP ( $1 \mathrm{~g}$ ) was added to petroleum ether (5 $\mathrm{ml}$ ) in a graduated cylinder and stirred $(5 \mathrm{~min})$. The cylinder was washed with petroleum ether $(1 \mathrm{ml})$ and the total volume (suspended particle and petroleum ether) recorded. The, PD of the ENP was calculated as follows:

\section{$P D=$ powder weight/total volume of suspended particle and petroleum ether-6}

\section{6. Packing Properties}

Bulk density (BD), tapped density (TD), Hausner ratio (HR), Carr index (CI), and porosity (PO) were measured as described by Santhalakshmy et al. ${ }^{19}$ Briefly, the ENP ( $2 \mathrm{~g})$ was loaded into a graduated cylinder $(10 \mathrm{ml})$ and the ratio of the mass of the ENP and the volume occupied was determined as the BD. The TD was determined, by vortexing the cylinder for $1 \mathrm{~min}$ and the volume occupied was used to calculate the TD. The HR, CI, and PO of the ENP were calculated as follows:

$$
\begin{aligned}
& H R=\text { tapped density/bulk density } \\
& C I=(\text { tapped density-bulk density/ } \\
& \text { tapped density }) \times 100 \\
& P O=(\text { particle density-tapped density/ } \\
& \text { particle density }) \times 100
\end{aligned}
$$

\section{7. Reconstitution Properties}

Water solubility index (WSI) and wettability time (WET) were measured according to Santhalakshmy et al. ${ }^{19}$ Briefly, the ENP (2.5 g) was added to distilled water $(30 \mathrm{ml}$, $30{ }^{\circ} \mathrm{C}$ ), vortex (15 min), and then centrifuged (9056 g, 10 min). The supernatant was collected in a petri dish and oven dried $\left(105^{\circ} \mathrm{C}, 8 \mathrm{~h}\right)$. The WSI of the ENP was expressed as a percentage according to the following equation:

WSI $=($ dry weight of supernatant/dry weight of $E N P) \times 100$
WET was determined by recording the time for complete wetting of the ENP ( $1 \mathrm{~g})$ deposited on the surface of the distilled water $\left(400 \mathrm{ml}, 25^{\circ} \mathrm{C}\right)$.

\section{8. Shelf-life Properties}

Moisture content (MC), hygroscopicity (HG), glass transition temperature (GT), and water activity (WA) were measured according to Santhalakshmy et al. ${ }^{19}$

MC of the ENP was measured gravimetrically (105 ${ }^{\circ} \mathrm{C}, 24 \mathrm{~h}$ ) and expressed as a percentage of dry basis. For the determination of the HG, the ENP ( $1 \mathrm{~g}$ ) was stored (at $25{ }^{\circ} \mathrm{C}$ ) for 7 days in a container containing a saturated solution of $\mathrm{NaCl}$ ( $75 \%$ relative humidity). The $\mathrm{HG}$ of the ENP was expressed as a percentage of $1 \mathrm{~g}$ of adsorbed moisture per $100 \mathrm{~g}$ of the sample on dry basis. The GT of the ENP was measured using a Differential Scanning Calorimeter (DSC S-650, Scinco, Seoul, Korea) calibrated with indium $\left(156.6^{\circ} \mathrm{C}\right)$ and purge with dry nitrogen $(50$ $\mathrm{ml} / \mathrm{min}$ ). The test was conducted from $-20{ }^{\circ} \mathrm{C}$ to $200{ }^{\circ} \mathrm{C}$ (heating rate of $10^{\circ} \mathrm{C} / \mathrm{min}$ ) using an empty aluminum pan as a reference. The glass transition midpoint was reported as the GT. The WA of the ENP was measured at $25^{\circ} \mathrm{C}$ using a water activity meter Aqualab 4TE (Decagon Devices, Washington, USA).

\section{9. Chromatic Properties}

The chromatic properties of the ENP were measured using a Hunterlab colorimeter (Color Quest XE, Reston, USA) and expressed as $L^{*}$ (lightness/darkness), $a^{*}$ (redness/greenness), and $b^{*}$ (yellowness/blueness). The chroma $\left(C^{*}\right)$ and hue $\left(H^{\circ}\right)$ were calculated as follows:

$$
\begin{aligned}
& C^{*}=\left(a^{* 2}+b^{* 2}\right)^{(1 / 2)} \\
& H^{\circ}=\tan ^{-1}\left(b^{*} / a^{*}\right)
\end{aligned}
$$

\section{10. Statistical Analysis}

All experiment and assays were done thrice. Tukey test for statistical difference and Pearson correlation were assessed at 5\% level using OriginPro 2017 (OriginLab, Northampton, USA).

\section{Results and Discussion \\ 3. 1. Influence of Carrier Materials on Chemical Properties}

\section{1. 1. Influence of Carrier Materials on Nutraceuticals Retention}

In order to assess the effect of the encapsulating agents on the level of NR, a comparative analysis was done between the biocompounds content of the NE and the 
ENP. The ENP had similar nutraceuticals profile (phenolic acids, flavonols, DNJ and GABA) to that of the NE (Table 1). All the ENP assessed in this work presented high NR (ranging from 66.09 to $97.86 \%$ ) of the targeted bioactive compounds (Fig. 1). Similar retention of phenolic compounds through freeze drying have been reported in literature. ${ }^{20-22}$

With respect to the wall material, the type of carrier was noted to have significantly $(p<0.0001)$ altered the nutraceutical content. As graphically illustrated in Fig. 1, encapsulation using MD provided the highest NR of phenolic acids (96.16 to $97.86 \%$ for CHA; 88.89 to $90.45 \%$ for $\mathrm{CA}$ ) and DNJ (95.57 to $97.80 \%$ ) as compared to the CMC which resulted in the highest NR of flavonols (83.87 to $88.35 \%$ for K3M; 75.93 to $82.75 \%$ for K3R; 84.39 to $85.75 \%$ for K3G; 80.27 to $83.85 \%$ for K7G; 87.97 to $90.88 \%$ for Q3R; 91.67 to $92.89 \%$ for Q3M; 95.03 to $97.75 \%$ for Q3G, and GABA 86.67 to $92.45 \%$ ). Stoll et al. ${ }^{23}$ also observed differences in the retention of individual anthocyanins with different wall materials during freeze-drying of grape pomace extract. This discrepancy in NR could be attributed to the formation of complexes between the biomolecule and polysaccharides. As stated by Laine et al., ${ }^{24}$ biocompounds may form complexes with polysaccharides depending on the nature of the core compounds (hydrophil- ic/hydrophobic character, and positive/negative charge), and the chemical structure of the carrier agent (conformational mobility and molecular size). Hence, the hydrophobic properties of $\mathrm{CMC}^{25}$ could explain its better retention of flavonols and GABA, while the hydrophilic properties of $\mathrm{MD}^{26}$ could account for its better retention of DNJ and phenolic acids. A similar observation has been reported by Stănciuc et al. ${ }^{27}$

Regarding the effect of addition rate of the encapsulating agent, the carrier concentration was found to have a significant effect $(p<0.0001)$ on the nutraceutical content. In line with Oberoi et al. ${ }^{28}$ an increase in carrier concentration resulted in a decrease in NR (Fig. 1). This might have resulted from the dilution of the nutraceutical content, due to the addition rate of wall material since the amount of NE was kept constant.

Moreover, the two-way ANOVA analysis highlighted a significant interactive effect between the type of wall material and the carrier concentration $(p<0.0001 \mathrm{CHA}$ and $\mathrm{K} 3 \mathrm{G} ; p<0.001 \mathrm{CA}, \mathrm{K} 3 \mathrm{R}, \mathrm{Q} 3 \mathrm{R}$, and Q3M; $p<0.05 \mathrm{~K} 3 \mathrm{M}$, $\mathrm{K} 7 \mathrm{G}$, and GABA) on the NR. This implies that significant quantity of the nutraceuticals remained at the surface of the capsules and were probably degraded during the freeze drying. As stated by Rajabi et al. ${ }^{8}$ and Garofulić et al., ${ }^{15}$ the interaction between wall material and carrier concentra-

Table 1. Nutraceuticals and antioxidant properties of encapsulated freeze-dried mulberry leaf extract powders

\begin{tabular}{|c|c|c|c|c|c|c|c|}
\hline \multirow{2}{*}{ Parameters } & \multicolumn{3}{|c|}{ CMC (\%) } & \multicolumn{3}{|c|}{ MD (\%) } & \multirow{2}{*}{ NE } \\
\hline & 0.55 & 0.70 & 0.85 & 08 & 10 & 12 & \\
\hline \multicolumn{8}{|c|}{ Phenolic acids (mg/g db) } \\
\hline $\mathrm{CHA}$ & $58.86 \pm 0.03^{\mathrm{e}}$ & $58.52 \pm 0.04^{\mathrm{f}}$ & $58.37 \pm 0.02^{\mathrm{g}}$ & $60.77 \pm 0.03^{b}$ & $59.96 \pm 0.04^{c}$ & $59.72 \pm 0.02^{\mathrm{d}}$ & $62.10 \pm 0.06^{\mathrm{a}}$ \\
\hline CA & $28.25 \pm 0.01^{\mathrm{e}}$ & $28.14 \pm 0.03^{\mathrm{f}}$ & $27.93 \pm 0.01^{g}$ & $29.13 \pm 0.02^{\mathrm{b}}$ & $29.00 \pm 0.04^{c}$ & $28.63 \pm 0.04^{\mathrm{d}}$ & $32.21 \pm 0.06^{\mathrm{a}}$ \\
\hline \multicolumn{8}{|c|}{ Flavonols (mg/g db) } \\
\hline $\mathrm{K} 3 \mathrm{M}$ & $44.33 \pm 0.07^{\mathrm{b}}$ & $43.18 \pm 0.04^{c}$ & $42.09 \pm 0.06^{\mathrm{d}}$ & $41.04 \pm 0.04^{\mathrm{e}}$ & $39.92 \pm 0.05^{\mathrm{f}}$ & $39.06 \pm 0.06^{\mathrm{g}}$ & $50.18 \pm 0.12^{\mathrm{a}}$ \\
\hline $\mathrm{K} 3 \mathrm{R}$ & $35.19 \pm 0.06^{\mathrm{b}}$ & $33.69 \pm 0.07^{c}$ & $32.29 \pm 0.05^{\mathrm{d}}$ & $31.16 \pm 0.09^{\mathrm{e}}$ & $29.98 \pm 0.05^{f}$ & $28.10 \pm 0.06^{\mathrm{g}}$ & $42.52 \pm 0.09^{\mathrm{a}}$ \\
\hline $\mathrm{K} 3 \mathrm{G}$ & $56.83 \pm 0.05^{\mathrm{b}}$ & $56.55 \pm 0.07^{c}$ & $55.93 \pm 0.07^{\mathrm{d}}$ & $51.47 \pm 0.05^{\mathrm{e}}$ & $50.64 \pm 0.07^{f}$ & $49.73 \pm 0.03^{g}$ & $66.27 \pm 0.06^{\mathrm{a}}$ \\
\hline K7G & $16.18 \pm 0.04^{\mathrm{b}}$ & $15.81 \pm 0.05^{\mathrm{c}}$ & $15.49 \pm 0.06^{\mathrm{d}}$ & $14.68 \pm 0.04^{\mathrm{e}}$ & $14.09 \pm 0.06^{\mathrm{f}}$ & $13.77 \pm 0.05^{g}$ & $19.30 \pm 0.04^{\mathrm{a}}$ \\
\hline Q3R & $14.26 \pm 0.09^{b}$ & $14.04 \pm 0.05^{\mathrm{c}}$ & $13.80 \pm 0.05^{\mathrm{d}}$ & $13.26 \pm 0.09^{e}$ & $12.81 \pm 0.08^{f}$ & $12.29 \pm 0.06^{\mathrm{g}}$ & $15.69 \pm 0.07^{\mathrm{a}}$ \\
\hline Q3M & $60.55 \pm 0.04^{\mathrm{b}}$ & $60.23 \pm 0.06^{\mathrm{c}}$ & $59.76 \pm 0.05^{\mathrm{d}}$ & $59.61 \pm 0.04^{\mathrm{e}}$ & $58.99 \pm 0.05^{f}$ & $58.76 \pm 0.04^{\mathrm{g}}$ & $65.19 \pm 0.06^{\mathrm{a}}$ \\
\hline Q3G & $31.65 \pm 0.07^{b}$ & $31.17 \pm 0.07^{c}$ & $30.77 \pm 0.08^{\mathrm{d}}$ & $30.36 \pm 0.06^{\mathrm{e}}$ & $29.96 \pm 0.05^{f}$ & $29.67 \pm 0.05^{\mathrm{g}}$ & $32.38 \pm 0.11^{\mathrm{a}}$ \\
\hline \multicolumn{8}{|c|}{ Other nutraceutical compounds ( $m g / g d b)$} \\
\hline DNJ & $14.56 \pm 0.03^{\mathrm{e}}$ & $14.30 \pm 0.04^{\mathrm{f}}$ & $14.10 \pm 0.05^{\mathrm{g}}$ & $15.24 \pm 0.03^{b}$ & $15.09 \pm 0.04^{\mathrm{c}}$ & $14.89 \pm 0.05^{\mathrm{d}}$ & $15.58 \pm 0.07^{\mathrm{a}}$ \\
\hline GABA & $4.67 \pm 0.01^{\mathrm{b}}$ & $4.48 \pm 0.02^{\mathrm{c}}$ & $4.38 \pm 0.04^{\mathrm{d}}$ & $4.24 \pm 0.01^{\mathrm{e}}$ & $4.14 \pm 0.03^{\mathrm{f}}$ & $4.04 \pm 0.04^{\mathrm{g}}$ & $5.05 \pm 0.04^{\mathrm{a}}$ \\
\hline \multicolumn{8}{|c|}{ Antioxidant activities $(\mathrm{mM} / \mathrm{g} d b)$} \\
\hline ABTS & $31.58 \pm 0.09^{\mathrm{e}}$ & $30.05 \pm 0.20^{\mathrm{f}}$ & $29.18 \pm 0.17^{g}$ & $37.56 \pm 0.08^{b}$ & $37.04 \pm 0.12^{c}$ & $35.16 \pm 0.12^{\mathrm{d}}$ & $39.98 \pm 0.14^{\mathrm{a}}$ \\
\hline CUPRAC & $53.44 \pm 0.22^{\mathrm{b}}$ & $51.98 \pm 0.24^{\mathrm{c}}$ & $50.95 \pm 0.12^{\mathrm{d}}$ & $48.38 \pm 0.18^{\mathrm{e}}$ & $47.80 \pm 0.18^{f}$ & $46.07 \pm 0.12^{\mathrm{g}}$ & $58.93 \pm 0.21^{\mathrm{a}}$ \\
\hline DPPH & $89.25 \pm 0.03^{e}$ & $85.23 \pm 0.03^{f}$ & $83.27 \pm 0.06^{\mathrm{g}}$ & $95.02 \pm 0.06^{b}$ & $94.74 \pm 0.07^{c}$ & $92.56 \pm 0.08^{d}$ & $101.33 \pm 0.10^{\mathrm{a}}$ \\
\hline FRAP & $219.46 \pm 0.28^{b}$ & $211.69 \pm 0.33^{c}$ & $205.26 \pm 0.16^{\mathrm{d}}$ & $201.67 \pm 0.13^{\mathrm{e}}$ & $200.07 \pm 0.15^{\mathrm{f}}$ & $193.63 \pm 0.17^{\mathrm{g}}$ & $233.77 \pm 0.23^{\mathrm{a}}$ \\
\hline
\end{tabular}

Values with different letters in the same row are significantly different at $p<0.05$ (Anova, Tukey's test)

CHA-chlorogenic acid, CA-caffeic acid, K3M-kaempferol-3-(6-malonylglucoside), K3R-kaempferol-3-(6-rhamnosylglucoside), K3G-kaempferol-3-glucoside, K7G- kaempferol-7-O-glucoside, Q3R-quercetin-3-rutinose, Q3M-quercetin-3-(6-malonylglucoside), Q3G-quercetin-3-O-glucoside, DNJ-1-deoxynojirimycin, GABA-gamma-aminobutyric acid, ABTS-2,2-azino-bis-(3-ethylbenzothiazoline-6-sulfonic acid), CUPRAC-cupric ion reducing capacity, DPPH-1,1-diphenyl-2-picrylhydrazyl, FRAP-ferric reducing antioxidant power capacity, CMC-sodium carboxymethyl cellulose, MD-maltodextrin, and NE-nutraceutical-dried extract 
a)

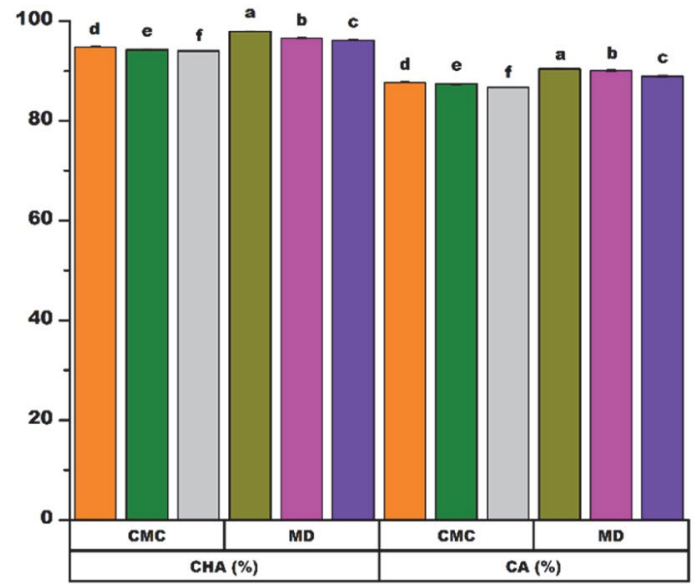

c)

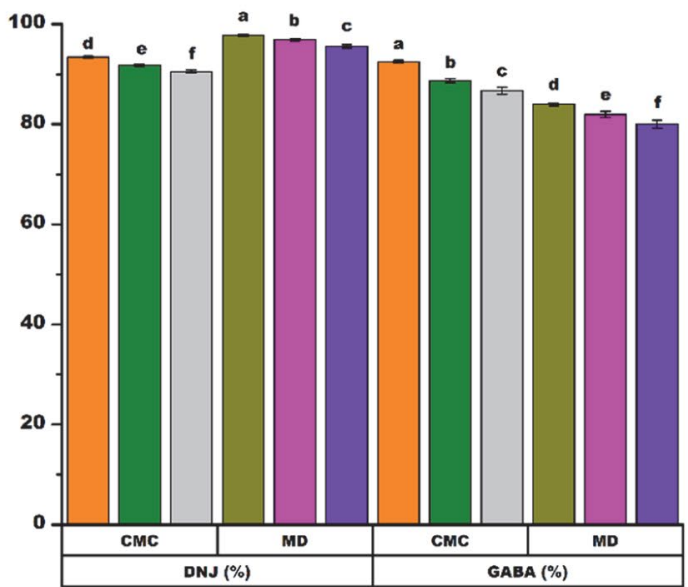

b)
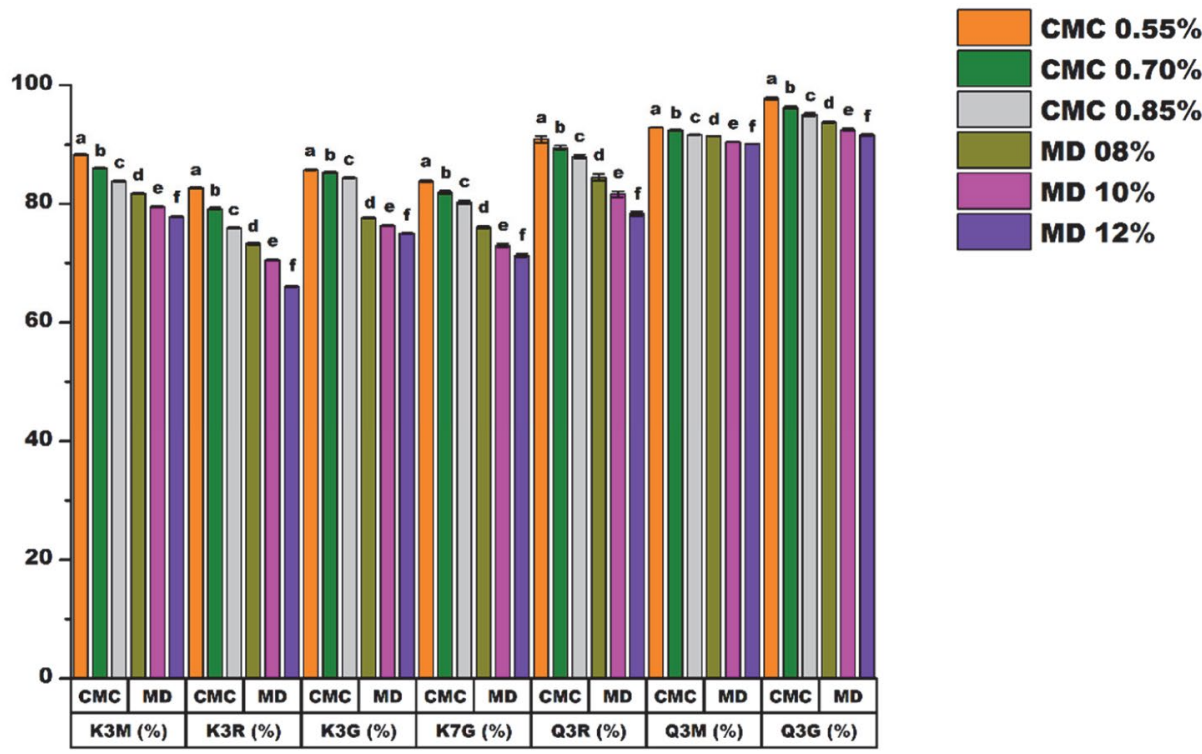

Figure 1. Phenolic acids (a), flavonols (b), and other nutraceutical compounds (c) retention of encapsulated freeze-dried mulberry leaf extract powders

CHA-chlorogenic acid, CA-caffeic acid, K3G-kaempferol-3-glucoside, K3M-kaempferol-3-(6-malonylglucoside), K3R-kaempferol-3-(6-rhamnosylglucoside), K7G- kaempferol-7-O-glucoside, Q3G-quercetin-3-O-glucoside, Q3M-quercetin-3-(6-malonylglucoside), Q3R-quercetin-3-rutinose, DNJ-1-deoxynojirimycin, GABA-gamma-aminobutyric acid, CMC- sodium carboxymethyl cellulose, and MD-maltodextrin

tion significantly influence the layer formation around the particles during encapsulation.

\section{1. 2. Influence of Carrier Materials on Encapsulation Retention}

The encapsulation data (Fig. 2) shows that the entrapment of the nutraceuticals inside the matrix was significantly $(p<0.05)$ dependent on the type of encapsulating agent and carrier concentration.

In terms of the carrier type, MD was more capable in encapsulating phenolic acids (94.37 to $95.79 \%$ for CHA; 91.35 to $94.00 \%$ for CA) and DNJ (68.70 to $71.54 \%)$ as compared to the CMC which had a greater ability to entrap the flavonols $(87.58$ to $89.64 \%$ for K3M; 80.82 to $82.36 \%$ for K3R; 86.06 to $87.87 \%$ for K3G; 84.41 to $86.82 \%$ for K7G; 92.68 to $93.51 \%$ for Q3R; 94.45 to $95.99 \%$ for Q3M; 96.32 to $97.83 \%$ for Q3G) and GABA (67.82 to $69.15 \%)$. As reported in literature ${ }^{29,30}$ the EE of biocompounds depends on the class of biocompounds and the type of coating material. Hence, this dissimilarity in EE could be ascribed to the chemical morphology of each wall material. The presence of several hydrophilic groups and shorter chains of MD makes it more appropriate for the encapsulation of the hydrophilic biocompounds (phenolic acids and DNJ) owing to the formation of solid network through electrostatic interaction. ${ }^{15,24}$ Besides, the affinity of the CMC towards the flavanols and GABA might be ascribed to the formation of hydrophobic interactions which might have resulted in an increase in their solubility due to the disruption of their crystal structure. ${ }^{31}$ This behavior was more evident in the entrapment of quercetin glyco- 
a)

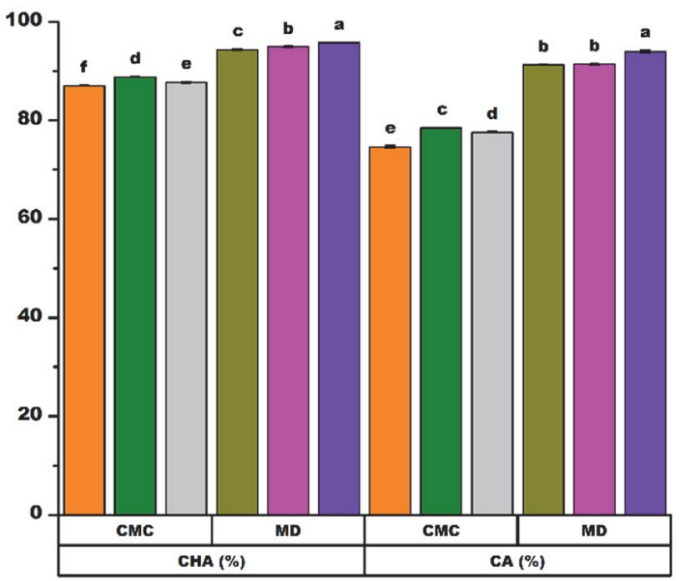

c)

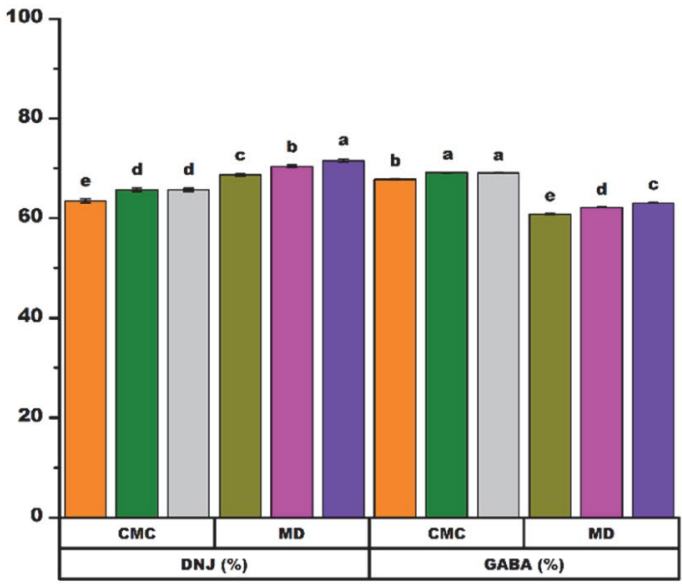

b)
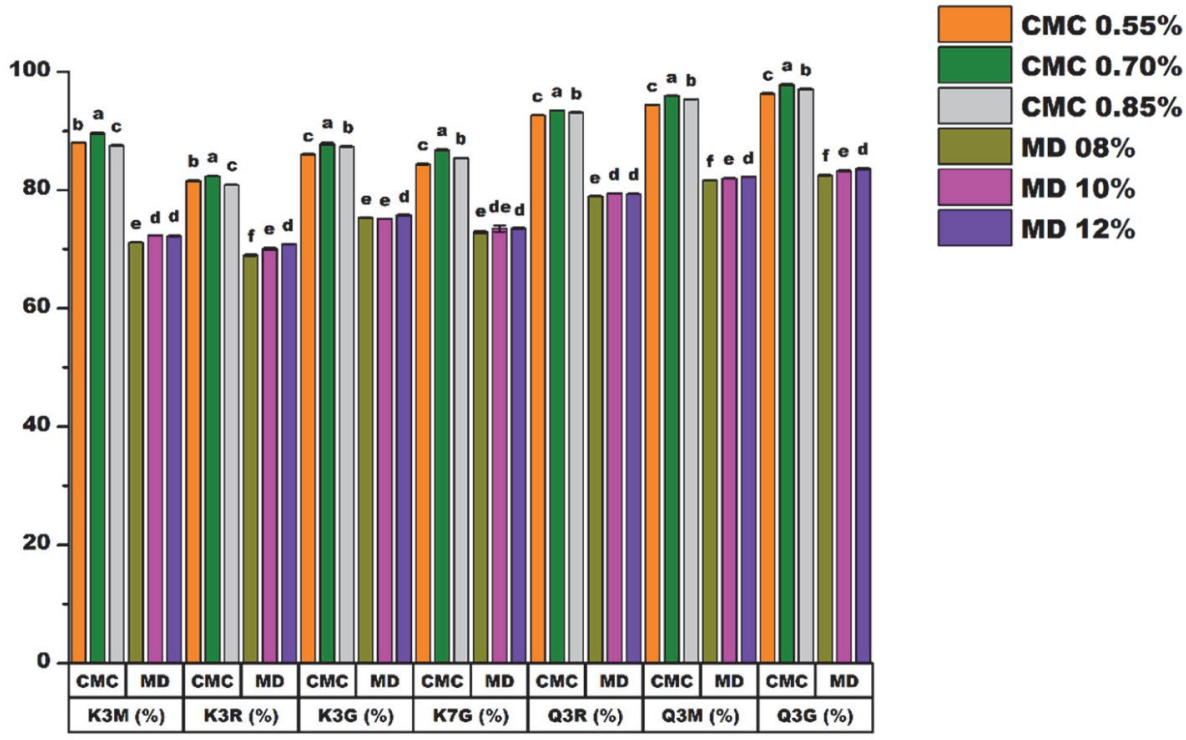

Figure 2. Phenolic acids (a), flavonols (b), and other nutraceutical compounds (c) encapsulation efficiency of encapsulated freeze-dried mulberry leaf extract powders

CHA-chlorogenic acid, CA-caffeic acid, K3G-kaempferol-3-glucoside, K3M-kaempferol-3-(6-malonylglucoside), K3R-kaempferol-3-(6-rhamnosylglucoside), K7G- kaempferol-7-O-glucoside, Q3G-quercetin-3-O-glucoside, Q3M-quercetin-3-(6-malonylglucoside), Q3R-quercetin-3-rutinose, DNJ-1-deoxynojirimycin, GABA-gamma-aminobutyric acid, CMC- sodium carboxymethyl cellulose, and MD-maltodextrin

sides (91.68 to $97.83 \%)$ than kaempferol glycosides (80.92 to $89.64 \%$ ) because of the quercetin planar three-dimensional structure. ${ }^{15}$

Furthermore, the addition rate of the carriers $(p<$ $0.0001)$ and the interactive effect of the carrier concentration and the carrier type $(p<0.0001$ for CHA, CA, K3M, K3R, K3G, Q3M, Q3G, and GABA; $p<0.001$ for K7G and Q3R; $p<0.05$ for DNJ) significantly impact on the EE. According to Peanparkdee et al., ${ }^{12}$ an increase in carrier concentration results in an increase in EE due to the addition of more functional groups (hydrophobic/ hydrophilic) which leads to more interactions (electrostatic/hydrogen bonding) between the polymer and the active compounds. Furthermore, the sublimation of water during freeze drying results in pore formation in the particles, thus resulting in a premature release of en- trapped nutraceuticals hence their degradation. ${ }^{22,29}$ As reported by some researchers, ${ }^{11,32,33}$ the type of carrier affects the viscosity of the feed mixture, thus impacting on the freezing rate which is related to ice crystals formation. The larger the ice crystals, the bigger the pore diameters of the freeze-dried particles. ${ }^{34}$ Therefore, as portrayed in Fig. 2, an increase in MD concentration resulted in a higher EE of the nutraceutical compounds. On the contrary, increasing the $\mathrm{CMC}$ concentration more than a threshold of $0.70 \% \mathrm{w} / \mathrm{v}$ led to a decrease in the EE of the biocompounds (Fig. 2). This behavior could be ascribed to the long-term aeration of the sample due to the high molar mass of CMC, which might have modified the viscosity of the feed mixture, thereby elongating the formation of ice crystals. Similar behavior was reported by Ogrodowska et al..$^{35}$ 


\section{1. 3. Influence of Carrier Materials on Antioxidant Properties}

The antioxidant activities (AA) of the ENP are shown in Table 1 . The type of wall material $(p<0.0001)$, the core to wall ratio $(p<0.0001)$, and their interaction significantly $(p<0.0001$ for ABTS, DPPH and FRAP; $p<0.05$ for CUPRAC) altered the AA of the ENP. This might be attributed to the direct correlation between the retained nutraceuticals and AA as reported by others authors. ${ }^{21,29}$ This assertion was buttressed by the strong significant correlation noted between the AA and CHA (ABTS: $r=0.971$ and DPPH: $r=0.940$ ); CA (ABTS: $r=0.990$ and DPPH: $r=$ 0.964); K3M (CUPRAC: $r=0.990$ and FRAP: $r=0.981$ ); K3R (CUPRAC: $r=0.987$ and FRAP: $r=0.984)$; K3G (CUPRAC: $r=0.972$ and FRAP: $r=0.894) ;$ K7G (CUPRAC: $r=$ 0.990 and FRAP: $r=0.947$ ); Q3R (CUPRAC: $r=0.984$ and FRAP: $r=0.940$ ); Q3M (CUPRAC: $r=0.967$ and FRAP: $r$ $=0.964) ; \mathrm{Q} 3 \mathrm{G}$ (CUPRAC: $\mathrm{r}=0.989$ and FRAP: $\mathrm{r}=0.983$ ); DNJ (ABTS: $r=0.991$ and DPPH: $r=0.992$ ) and GABA (CUPRAC: $r=0.988$ and FRAP: $r=0.988$ ). Similar correlations have been reported for freeze-dried powder. ${ }^{29,30}$

\section{2. Influence of Carrier Materials on Physical Properties}

\section{2. 1. Effect of Carrier Materials on Particle Properties}

According to Kuck et al., ${ }^{22}$ PS of encapsulated powders depends on the concentration and the type of wall material. In agreement with this, the type of carrier agent $(p<0.0001)$ and the addition rate of carrier $(p<0.0001)$ significantly impacted on the PS of the ENP. As depicted in Fig. 3a, an increase in carrier concentration led to larger particle size. This could be as a result of the enhancement of the aggregation of the particles resulting from the formation of bridges between molecules due to the increase in total solid content. ${ }^{11,17,22}$ The effect of the carrier type on PS may be attributed to their molecular weights which could have altered the freezing point, thereby impacting on the ice crystal size and sublimation rate hence the difference in the PS. ${ }^{11,32,33}$

PD has been reported to be related to the viscosity and occluded air density. ${ }^{36}$ Therefore, the significant effect of the carrier type $(p<0.0001)$ on PD of the ENP could be attributed to the differences in their molar mass, which might have modified the viscosity of the feed mixture. ${ }^{37}$ In this study, the PD was significantly influenced $(p<0.0001)$ by the addition rate of the carrier. In line with Seerangurayar et al., ${ }^{11}$ increasing the concentration of the wall material resulted in lower PD (Fig. 3a). This might have resulted from the increment in occluded air in the particle, due to the increase in feed viscosity which could have resulted in particulate inflation-ballooning. ${ }^{38,39}$ This statement was buttressed by the significant positive correlation between PS and PD $(r=0.868)$.

\section{2. 2. Effect of Carrier Materials on Packing Properties}

The type of encapsulating agent $(p<0.0001)$, addition rate of the carrier $(p<0.0001)$, and their interaction $(p$ $<0.001$ for BD; $p<0.0001$ for TD) showed significant effect on the BD and TD of the ENP. According to Celli et al., ${ }^{40}$ the effect of encapsulating agents on BD may be ascribed to their impact on crystals formation during lyophilization. As illustrated in Fig. 3b, the BD and the TD increased with increasing proportion of the encapsulating agents. Caliskan et al., ${ }^{41}$ reported that, the residual MC of freeze-dried powder influences the $\mathrm{BD}$, as particulates with higher MC might lead to incomplete dry agglomerate with bigger particles, thus resulting in a lower BD. Furthermore, the increase in TD with an increase in carrier concentration may be accredited to size enlargement of powder particles, as smaller particles could easily occupy inter-particle voids during tapping. ${ }^{11}$ These assertions were buttressed by the significant negative correlations found between MC and BD ( $r=-0.989)$ as well as PS and $\mathrm{TD}(\mathrm{r}=-0.853)$.

The wall materials $(p<0.0001)$, carrier concentration $(p<0.0001)$, and their interactive $(p<0.0001)$ effects were found to have significantly impacted on the HR and the CI of the ENP. In line with earlier reports, ${ }^{11,41}$ the HR and the $\mathrm{CI}$ decreased with increasing addition rate of the wall material (Fig. $3 b \& c$ ). Based on the classification of powder flowability expressed as CI (very bad: $>45 \%$, bad: $35-45 \%$, passable: $20-35 \%$, good: $15-20 \%$, and excellent: $<15 \%$ ) and powder cohesiveness expressed as HR (high: $>1.4$, intermediated: $1.2-1.4$, and low: $<1.2),{ }^{11,41}$ the ENP were found to be highly cohesive with fair flowability. According to Caliskan et al., ${ }^{41}$ increase in flowability properties of lyophilized powder could be ascribed to the impact of the encapsulating agents on the MC. Moreover, the increase in PS which is related to molar mass of carrier tends to reduce the cohesion due to the reduction in particle surface area per unit mass, thus inducing lower surface area for inter-particle interactions and bonding, thereby lessening HR and resulting in an upsurge in CI. ${ }^{38}$ These statements were supported by the significant positive correlation between MC $(r=0.975 ; 0.972)$ and PS $(r=0.834$; 0.833 ) with HR and CI, respectively.

The type of wall material $(p<0.0001)$, addition rate of the carrier $(p<0.0001)$, and their interaction $(p<0.05)$ significantly impacted on the PO of the ENP. PO is associated with $\mathrm{BD}$ since it assesses the fraction of total volume which is occupied by air. ${ }^{11,42}$ According, to Seerangurayar et al., ${ }^{11}$ an negative relationship between $\mathrm{PO}$ and $\mathrm{BD}$ indicates that the amount of air incorporated into the feed mixture promoted air accumulation within the dried particles, thereby making them more porous. ${ }^{11}$ Therefore, the effect of the carrier type on the PO may be credited to their skin-forming abilities. This statement was supported by the significant negative correlation between $\mathrm{PO}$ and $\mathrm{BD}(\mathrm{r}$ $=-0.994)$. Moreover, as mentioned above, the ice crystal

Tchabo et al.: Carrier Effects on the Chemical and Physical ... 
a)

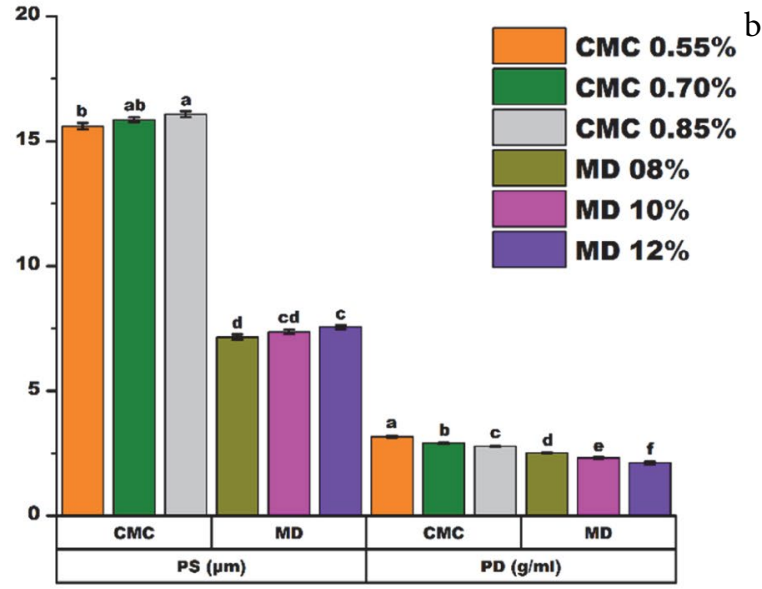

c)

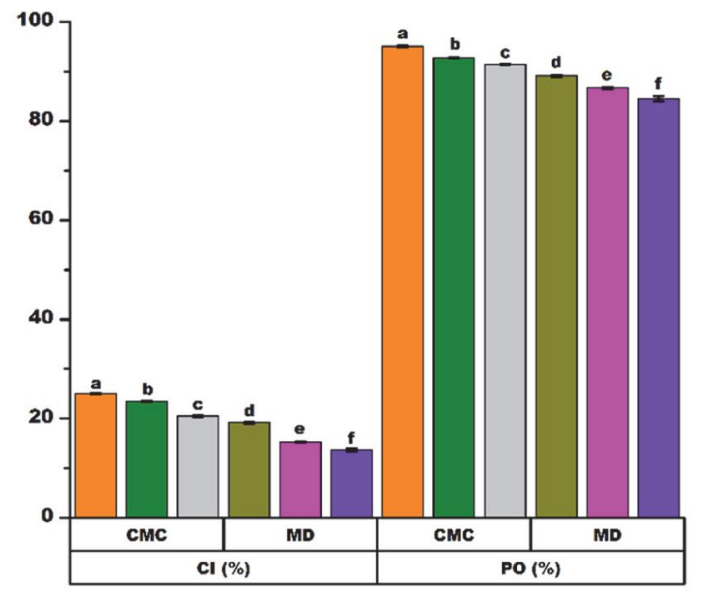

b)

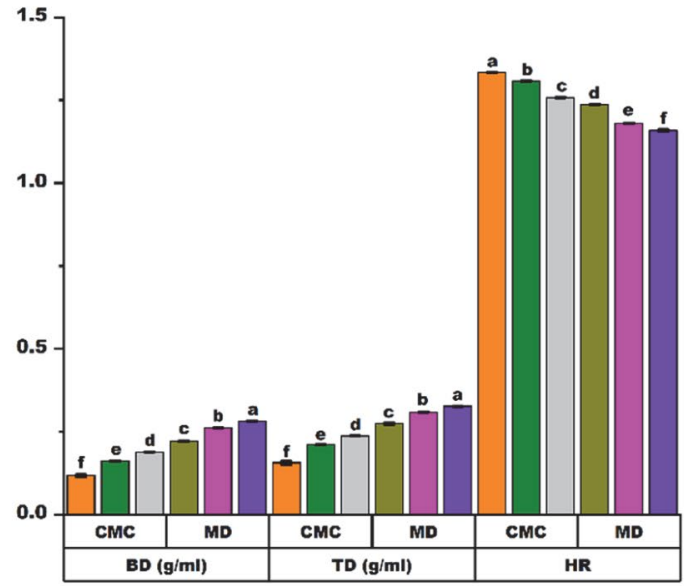

d)

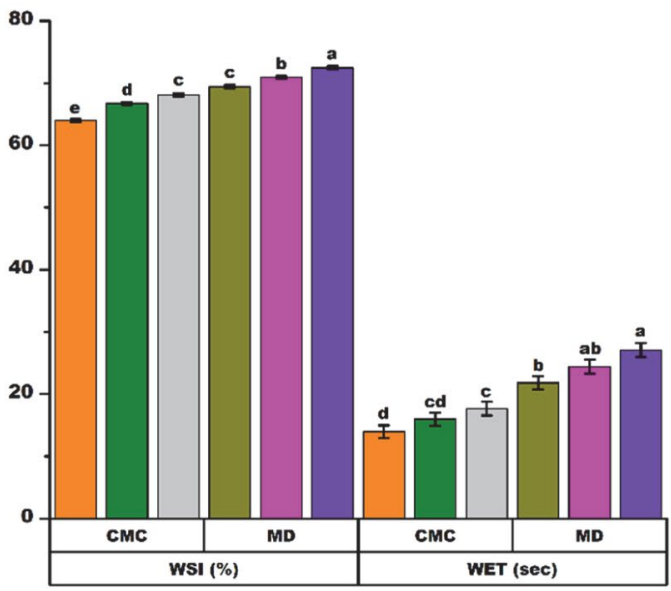

Figure 3. Effect of carriers on particle, packing and reconstitution properties of encapsulated freeze-dried mulberry leaf extract powders

PS-particle size, PD-particle density, BD-bulk density, TD-tapped density, HR-Hausner ratio, CI-Carr index, PO-porosity, WSI-water solubility index, WET-wettability time, CMC-sodium carboxymethyl cellulose, and MD-maltodextrin

size which is related to the type of carrier has been reported to be associated with PO. ${ }^{40}$ Hence, as shown in Fig. 3c, increasing carrier concentration led to a decrease in PO. According to Seerangurayar et al., ${ }^{11}$ high levels of carrier can cause substantial size enlargement and heavier particles, thereby filling the void spaces between agglomerates.

\section{2. 3. Effect of Carrier Materials on Reconstitution Properties}

The encapsulating materials $(p<0.0001)$, proportion of the carriers $(p<0.0001)$, and their interaction $(p<0.05)$ significantly alter the WSI of the ENP. According to Kuck et al., ${ }^{22}$ high WSI is related to small PS owing to the large surface area available for moisturizing. $\mathrm{MC}$ has been reported to be among the main factors that impacts on powder solubility, thus a lower MC results in high WSI. ${ }^{39}$ Therefore, the increase in WSI with an increase in the carrier concentration (Fig. 3d) may be ascribed to the effect of the addition rate of the encapsulating agent on PS and MC of the ENP. This was supported by the negative significant correlations between WSI and PS $(r=-0.820)$ as well as MC $(r=-0.998)$. Besides, the WSI of plant extract powder in an aqueous phase depends on the structure of the wall material. ${ }^{41}$ Therefore, as depicted in Fig. 3d, the effect of the carrier type on the WSI may be due to their inherent aqueous solubility and ability to withstand hydrophobic/ hydrophilic conditions. ${ }^{43}$ Moreover, increase in molar mass reduces diffusivity, hence materials with low diffusivity usually have low solubility. ${ }^{4}$

Large particles form wide pores, high porousness, and small contact angles between penetrating solvent and powder surface, which swift wetting by boosting solvent penetration into agglomerate. ${ }^{42,45}$ Selomulya et al. ${ }^{36}$ reported that granulation positively impacts on WET. Therefore, reduction in PD that occurred at high carrier concentration leads to reduction in powder compactness which accelerated infiltration of solvent in agglomerate, thus 
causing an increase in WET. ${ }^{46}$ Furthermore, caking which usually happens in powders with high MC may contribute to WET since it eases the passage of water through the pores. ${ }^{47}$ Hence, the significant effect of the type $(p<$ $0.0001)$ and addition rate of the wall material $(p<0.0001)$ on WET of the ENP could be attributed to their effect on PS, PO, PD, and MC of the ENP. This was supported by the negative significant correlations between WET and PS ( $\mathrm{r}=$ -0.899), PO ( $\mathrm{r}=-0.996), \mathrm{PD}(\mathrm{r}=-0.995)$, as well as MC ( $\mathrm{r}$ $=-0.973)$. In line with Caliskan et al., ${ }^{41}$ increasing in the carrier concentration resulted in an increment in WET of the ENP (Fig. 3d).

\section{2. 4. Effect of Carrier Materials on Shelf-life Properties}

The encapsulating agents $(p<0.0001)$, addition rate of wall material $(p<0.0001)$, and their interaction $(p<$ 0.05 ) had a significant effect on the MC of the ENP. A sim- ilar observation has been reported. ${ }^{11,48} \mathrm{An}$ increase in the addition rate of wall material resulted in a decrease in MC (Fig. 4a). This could be ascribed to the higher level of carrier concentration, which led to an increment in total solids of the feed mixture, thereby decreasing the amount of free water available for sublimation. ${ }^{38}$ This finding is consistent with earlier reports on freeze dry powders. ${ }^{11,28,48}$

The HG of freeze dry powder has been reported to be related to PS. The smaller the PS, the larger the surface area exposed to the ambient air, thus leading to more water absorption..$^{22}$ Furthermore, carrier materials have been proven to be less hygroscopic due to their high GT. ${ }^{45}$ Moreover, reduction in HG is linked to the carrier's molecular weight. ${ }^{11,38}$ Hence, the significant effect of the type $(p<$ $0.0001)$, the addition rate of wall material $(p<0.0001)$, and their interaction $(p<0.0001)$ on the HG may be related to their effect on PS and GT of the ENP. This was supported by the negative significant correlations between HG and PS $(r=-0.939)$ as well as GT $(r=-0.997)$. Further, in ac- a)

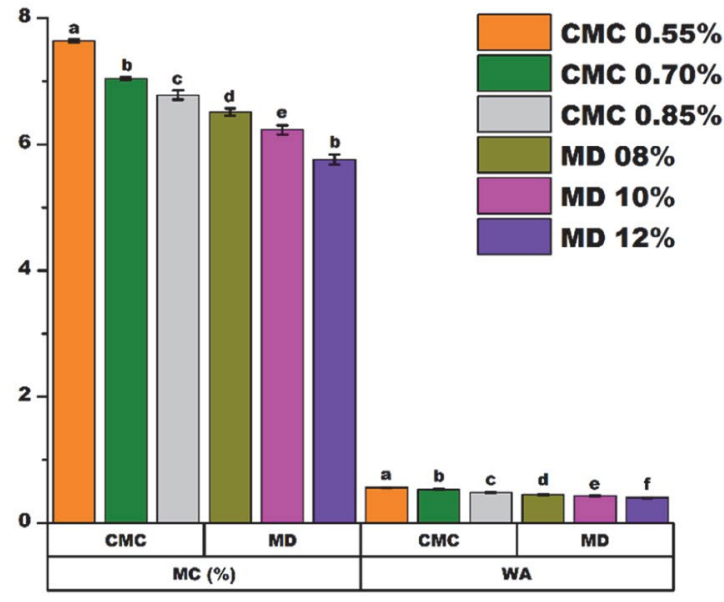

c)

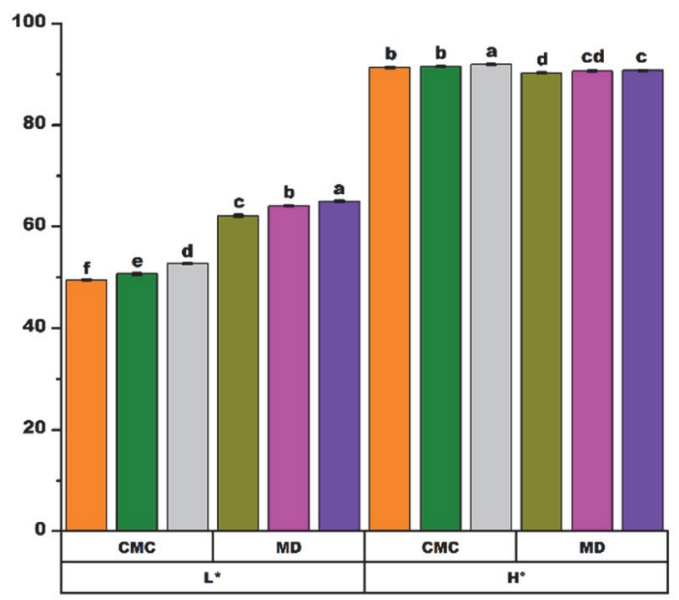

b)

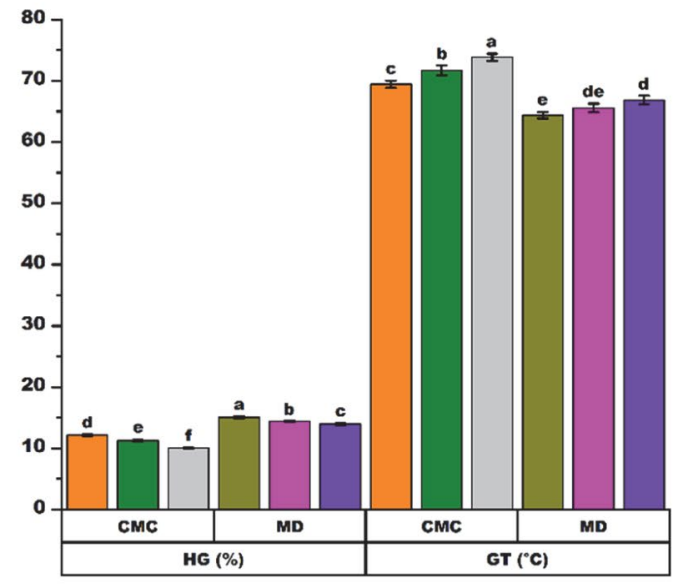

d)

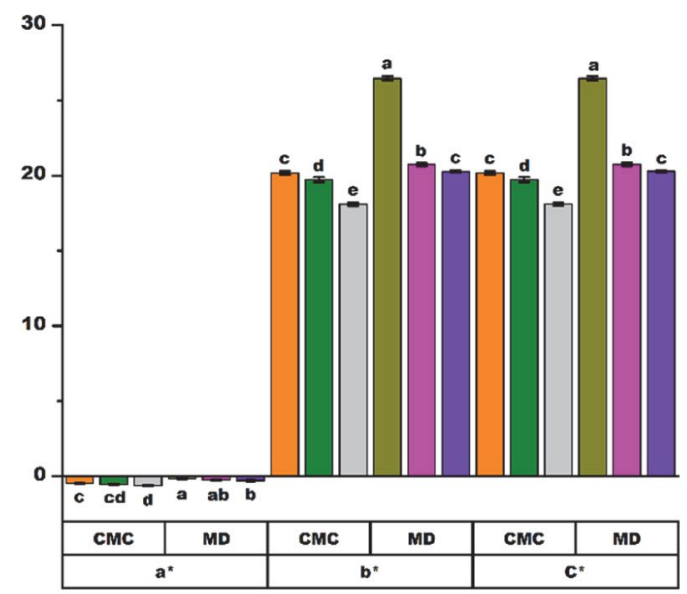

Figure 4: Effect of carriers on shelf-life and chromatic properties of encapsulated freeze-dried mulberry leaf extract powders

MC-moisture content, WA-water activity, HG-hygroscopicity, GT-glass transition temperature, $L^{*}$-lightness/darkness, $a^{*}$-redness/greenness, $b^{*}$-yellowness/blueness, $C^{*}$-chroma, $H^{\circ}$-Hue, CMC-sodium carboxymethyl cellulose, and MD-maltodextrin 
cordance with others authors, ${ }^{38,45}$ a decrease in HG was observed with an increase in the type and concentration of encapsulated agent used (Fig. 4b).

The type $(p<0.0001)$ and addition $(p<0.0001)$ of carrier significantly alter the GT of the ENP. According to Kuck et al., ${ }^{22}$ GT is affected by molecular weight of encapsulating agent. Consequently, the addition rate of the carrier led to an increase in the GT. ${ }^{49}$ Therefore, in agreement with previous authors, ${ }^{38,49}$ an increase in the ratio of encapsulating agents resulted in a higher GT (Fig. 4b). However, MC depresses GT by acting as a plasticizer, ${ }^{20}$ thus a decrease in GT resulted from an increase in the MC (Fig. $4 \mathrm{a} \& \mathrm{~b})$. Similar behavior was reported for freeze-dried mango pulp using maltodextrin as wall material. ${ }^{50}$ Furthermore, the decrease in GT may also be attributed to the high content of nutraceutical component in encapsulated powders. ${ }^{40}$

The type of wall material $(p<0.0001)$, addition rate of carrier $(p<0.0001)$, and their interaction $(p<0.05)$ significantly affected the WA of the ENP. WA has been linked to $\mathrm{MC}$, through sorption isotherms. ${ }^{49}$ According to Bitar et al., ${ }^{51}$ the moisture sorption isotherm highlights that initial absorbed water molecules could interact with binding sites of wall materials. Therefore, the impact of the carrier type on the WA may be due to their differences in water-binding capacity which is related to their chemical structure. ${ }^{11}$ This assertion was supported by the significant positive correlation between MC $(r=0.982)$ and WA. Furthermore, in line with previous reports, ${ }^{11,41}$ a decrease in WA was observed with an increase in carrier concentration (Fig. 4a).

\section{2. 5. Effect of Carrier Materials on Chromatic Properties}

The type of encapsulating agent $(p<0.0001)$, carrier concentration $\left(p<0.0001\right.$ for $L^{*}, b^{*}, C^{*}$, and $\mathrm{H}^{\circ} ; p<0.001$ for $\left.a^{*}\right)$, and their interaction ( $p<0.001$ for $L^{*} ; p<0.0001$ for $b^{*}$ and $C^{*}$ ) showed significant effect on the chromatic indices of the ENP. An increase in addition rate of encapsulating agent resulted in an increase in $L^{*}$ and $H^{\circ}$ (Fig. 4c) conversely to $a^{*}, b^{*}$, and $C^{*}$ (Fig. 4d). This behavior may be ascribed to the inherent white color and dilution effect induced by the higher addition rate of the coating material. ${ }^{45,52}$ Similar results have been reported by other researchers. ${ }^{28,38,45,52,53}$

\section{Conclusion}

Encapsulation of nutraceutical compounds from mulberry leaf extract with sodium carboxymethyl cellulose or maltodextrin as encapsulating agents efficiently reduced the loss of nutraceuticals. The results from this study demonstrated that the use of sodium carboxymethyl cellulose was more suitable for the retention of flavonols and gamma-aminobutyric acid, resulting in highest en- trapment efficiency of these bioactive components inside the matrix as compared to the maltodextrin which had a greater retention ability for the phenolic acids and 1-deoxynojirimycinin. Moreover, due to the effect of carriers on ice crystal formation, the core to wall ratio was found to be crucial with regards to the physical properties of the ENP. Regardless of the type of wall material, increasing the carrier concentration resulted in an increase in particle size, bulk density, tapped density, water solubility index, wettability time, and glass transition temperature conversely to the particle density, Hausner ratio, Carr index, porosity, moisture content, water activity, and hygroscopicity. The chromatic indexes of the ENP were mainly affected by the type of carrier material which led to the formation of a lighter and more greenish powder with an increase in addition rate of the carrier.

The current study demonstrated that sodium carboxymethyl cellulose and maltodextrin could be used as wall material for the production of a nutraceutical mulberry leaf powder with adequate characteristic to be utilized as a bioactive additive for the development of functional products in the food and nutraceutical industries. From an economic aspect and industrial level, the proposed encapsulation process was found to improve the physical properties of the powder which significantly influence the processing, storage, handling, packing, shipping, and commercialization cost.

\section{Conflict of Interest}

This manuscript has no conflict of interest.

\section{Acknowledgement}

This research did not receive any specific grant from funding agencies in the public, commercial, or not-forprofit sectors.

\section{References}

1. A. A. Memon, N. Memon, D. L. Luthria, M. I. Bhanger and A. A. Pitafi, Polish Journal of Food and Nutrition Sciences 2010, 60 .

2. Y. Huo, Mulberry for Animal Production, FAO Animal Production, and Health Paper 2002, 147, 11-43.

3. A. Gryn-Rynko, G. Bazylak and D. Olszewska-Slonina, Biomedicine \& Pharmacotherapy 2016, 84, 628-636. DOI:10.1016/j.biopha.2016.09.081

4. K. Nagalakshmamma, Journal of Pharmacy 2012, 2, 22503013.

5. S. Struck, M. Plaza, C. Turner and H. Rohm, Int. J. Food Sci. Tech. 2016, 51, 1305-1318. DOI:10.1111/ijfs.13112

6. L. Medina-Torres, R. Santiago-Adame, F. Calderas, J. Gal- 
legos-Infante, R. González-Laredo, N. Rocha-Guzmán, D. Núñez-Ramírez, M. Bernad-Bernad and O. Manero, Industrial Crops and Products 2016, 90, 1-8.

DOI:10.1016/j.indcrop.2016.06.009

7. F. Sansone, T. Mencherini, P. Picerno, M. d'Amore, R. P. Aquino and M. R. Lauro, Journal of Food Engineering 2011, 105, 468-476. DOI:10.1016/j.jfoodeng.2011.03.004

8. H. Rajabi, M. Ghorbani, S. M. Jafari, A. S. Mahoonak and G. Rajabzadeh, Food hydrocolloids 2015, 51, 327-337.

DOI:10.1016/j.foodhyd.2015.05.033

9. S. Ray, U. Raychaudhuri and R. Chakraborty, Food Bioscience 2016, 13, 76-83. DOI:10.1016/j.fbio.2015.12.009

10. A. C. P. Souza, P. D. Gurak and L. D. F. Marczak, Food Bioprod. Process. 2017, 102, 186-194.

DOI:10.1016/j.fbp.2016.12.012

11. T. Seerangurayar, A. Manickavasagan, A. M. Al-Ismaili and Y. A. Al-Mulla, J. Food Eng. 2017, 215, 33-43.

DOI:10.1016/j.jfoodeng.2017.07.016

12. M. Peanparkdee, S. Iwamoto, C. Borompichaichartkul, K. Duangmal and R. Yamauchi, Int. J. Food Sci. Tech. 2016, 51, 649-655. DOI:10.1111/ijfs.13032

13. C. G. Da Rosa, C. D. Borges, R. C. Zambiazi, M. R. Nunes, E. V. Benvenutti, S. R. da Luz, R. F. D’Avila and J. K. Rutz, Industrial crops and products 2013, 46, 138-146.

DOI:10.1016/j.indcrop.2012.12.053

14. M. I. Dias, I. C. Ferreira and M. F. Barreiro, Food \& function 2015, 6, 1035-1052. DOI:10.1039/C4FO01175A

15. I. E. Garofulić, Z. Zorić, S. Pedisić and V. Dragović-Uzelac, LWT-Food Science and Technology 2017, 83, 110-117.

DOI:10.1016/j.lwt.2017.05.017

16. W. Tchabo, Y. Ma, E. Kwaw, L. Xiao, M. Wu and A. T. Maurice, Int. J. Food Prop. 2018, 21, 717-732.

DOI:10.1080/10942912.2018.1446025

17. E. Akbas, M. Kilercioglu, O. N. Onder, A. Koker, B. Soyler and M. H. Oztop, Journal of Functional Foods 2017, 28, 19-27. DOI:10.1016/j.jff.2016.11.010

18. J. Du, Z.-Z. Ge, Z. Xu, B. Zou, Y. Zhang and C.-M. Li, Drying Technol. 2014, 32, 1157-1166.

DOI:10.1080/07373937.2014.886259

19. S. Santhalakshmy, S. J. D. Bosco, S. Francis and M. Sabeena, Powder Technol. 2015, 274, 37-43.

DOI:10.1016/j.powtec.2015.01.016

20. V. Sanchez, R. Baeza, M. V. Galmarini, M. C. Zamora and J. Chirife, Food and Bioprocess Technology 2013, 6, 1350-1354. DOI:10.1007/s11947-011-0654-z

21. L. F. Ballesteros, M. J. Ramirez, C. E. Orrego, J. A. Teixeira and S. I. Mussatto, Food Chem. 2017, 237, 623-631.

DOI:10.1016/j.foodchem.2017.05.142

22. L. S. Kuck and C. P. Z. Noreña, Food Chem. 2016, 194, 569576. DOI:10.1016/j.foodchem.2015.08.066

23. L. Stoll, T. M. H. Costa, A. Jablonski, S. H. Flôres and A. de Oliveira Rios, Food and bioprocess technology 2016, 9, 172181. DOI:10.1007/s11947-015-1610-0

24. P. Laine, P. Kylli, M. Heinonen and K. Jouppila, J. Agric. Food Chem. 2008, 56, 11251-11261. DOI:10.1021/jf801868h

25. C. G. Lopez, S. E. Rogers, R. H. Colby, P. Graham and J. T.
Cabral, J. Polym. Sci., Part B: Polym. Phys. 2015, 53, 492-501. DOI:10.1002/polb.23657

26. A. N. Negrão-Murakami, G. L. Nunes, S. S. Pinto, F. S. Murakami, E. R. Amante, J. C. C. Petrus, E. S. Prudêncio and R. D. M. C. Amboni, LWT - Food Science and Technology 2017, 79, 561-567. DOI:10.1016/j.lwt.2016.11.002

27. N. Stănciuc, M. Turturică, A. M. Oancea, V. Barbu, E. Ioniță, I. Aprodu and G. Râpeanu, Food and Bioprocess Technology 2017, 10, 1715-1726. DOI:10.1007/s11947-017-1938-8

28. D. P. S. Oberoi and D. S. Sogi, J. Food Eng. 2015, 165, 172-178. DOI:10.1016/j.jfoodeng.2015.06.024

29. Y. R. R. S. Rezende, J. P. Nogueira and N. Narain, Food Chem. 2018, 254, 281-291. DOI:10.1016/j.foodchem.2018.02.026

30. C. G. Da Rosa, C. D. Borges, R. C. Zambiazi, J. K. Rutz, S. R. da Luz, F. D. Krumreich, E. V. Benvenutti and M. R. Nunes, LWT-Food Science and Technology 2014, 58, 527-533.

DOI:10.1016/j.lwt.2014.03.042

31. B. Li, S. Konecke, K. Harich, L. Wegiel, L. S. Taylor and K. J. Edgar, Carbohydr. Polym. 2013, 92, 2033-2040.

DOI:10.1016/j.carbpol.2012.11.073

32. N. Harnkarnsujarit, S. Charoenrein and Y. H. Roos, Carbohydr. Polym. 2012, 88, 734-742.

DOI:10.1016/j.carbpol.2012.01.028

33. A. M. Ceballos, G. I. Giraldo and C. E. Orrego, J. Food Eng. 2012, 111, 360-365.

DOI:10.1016/j.jfoodeng.2012.02.010

34. M. J. Ramírez, G. I. Giraldo and C. E. Orrego, Powder Technol. 2015, 277, 89-96. DOI:10.1016/j.powtec.2015.02.060

35. D. Ogrodowska, M. Tańska and W. Brandt, Food and Bioprocess Technology 2017, 10, 1265-1280.

DOI:10.1007/s11947-017-1898-Z

36. C. Selomulya and Y. Fang: Handbook of Food Powders, Woodhead Publishing, Philadelphia, 2013, pp. 379-408.

DOI:10.1533/9780857098672.2.379

37. K. Samborska, P. Gajek and A. Kamińska-Dwórznicka, Polish Journal of Food and Nutrition Sciences 2015, 65, 109-118. DOI:10.2478/pjfns-2013-0012

38. S. Bhusari, K. Muzaffar and P. Kumar, Powder Technol. 2014, 266, 354-364. DOI:10.1016/j.powtec.2014.06.038

39. A. M. Goula and K. G. Adamopoulos, Drying Technol. 2008, 26, 726-737. DOI:10.1080/07373930802046377

40. G. B. Celli, R. Dibazar, A. Ghanem and M. S.-L. Brooks, Drying Technol. 2016, 34, 1175-1184.

\section{DOI:10.1080/07373937.2015.1099546}

41. G. Caliskan and S. N. Dirim, Powder Technol. 2016, 287, 308314. DOI:10.1016/j.powtec.2015.10.019

42. C. C. Ferrari, S. P. M. Germer, I. D. Alvim, F. Z. Vissotto and J. M. de Aguirre, Int. J. Food Sci. Tech. 2012, 47, 1237-1245.

DOI:10.1111/j.1365-2621.2012.02964.x

43. S. Murali, A. Kar, D. Mohapatra and P. Kalia, Food Sci. Technol. Int. 2015, 21, 604-612.

DOI:10.1177/1082013214557843

44. Q. Shi, Z. Fang and B. Bhandari, Drying Technol. 2013, 31, 1681-1692. DOI:10.1080/07373937.2013.783593

45. T. Seerangurayar, A. Manickavasagan, A. M. Al-Ismaili and Y. A. Al-Mulla, Drying Technol. 2017, 1-12.

Tchabo et al.: Carrier Effects on the Chemical and Physical ... 
46. R. V. d. B. Fernandes, D. A. Botrel, E. K. Silva, C. G. Pereira, E. L. d. Carmo, A. L. d. A. Dessimoni and S. V. Borges, Drying Technol. 2017, 35, 1098-1107.

DOI:10.1080/07373937.2016.1231690

47. R. V. d. B. Fernandes, S. V. Borges, D. A. Botrel and C. R. d. Oliveira, Int. J. Food Sci. Tech. 2014, 49, 1522-1529.

DOI:10.1111/ijfs.12449

48. S. Saikia, N. K. Mahnot and C. L. Mahanta, Food Chem. 2015, 171, 144-152. DOI:10.1016/j.foodchem.2014.08.064

49. L. E. Kurozawa, K. J. Park and M. D. Hubinger, J. Food Eng. 2009, 91, 287-296. DOI:10.1016/j.jfoodeng.2008.09.006
50. S. Fongin, K. Kawai, N. Harnkarnsujarit and Y. Hagura, J. Food Eng. 2017, 210, 91-97.

DOI:10.1016/j.jfoodeng.2017.04.025

51. M. Bitar, G. Roudaut, J. Maalouly, S. Brandès, R. D. Gougeon, P. Cayot and E. Bou-Maroun, React. Funct. Polym. 2017, 114, 1-7. DOI:10.1016/j.reactfunctpolym.2017.02.012

52. L. D. Daza, A. Fujita, C. S. Fávaro-Trindade, J. N. Rodrigues-Ract, D. Granato and M. I. Genovese, Food Bioprod. Process. 2016, 97, 20-29. DOI:10.1016/j.fbp.2015.10.001

53. V. T. Šaponjac, G. Ćetković, J. Čanadanović-Brunet, S. Djilas, B. Pajin, J. Petrović, S. Stajčić and J. Vulić, Acta Chimica Slovenica 2017, 64, 283-289. DOI:10.17344/acsi.2016.2789

\section{Povzetek}

Ekstrakt iz listov murve smo inkapsulirali z natrijkarboksimetil celulozo $(0.55 \%, 0.70 \%$ in $0.75 \% \mathrm{w} / \mathrm{v})$ ali maltodekstrinom $(8 \%, 10 \%$ in $12 \% \mathrm{w} / \mathrm{v})$. Izsledki raziskav so pokazali, da je inkapsulacija z maltodekstrinom bolj učinkovita za fenolne kisline in 1-deoksinojirimicin medtem ko so flavonoli in gama-aminobutanojska kislina bolje inkapsulirani z natrijkarboksimetil celulozo. Pokazali smo tudi, da so antioksidativne lastnosti uprašenih inkapsulatov povezane z njihovimi hranilnimi sestavinami. Prah pridobljen iz natrijkarboksimetil celuloznega inkapsulata je izkazoval primerno higroskopnost, čas omakanja, temperaturo steklastega prehoda in snovne lastnosti, medtem ko je prah pridobljen iz maltodekstrina izkazoval željeno poroznost, vodotopnost, vsebnost vlage, vodno aktivnost, barvo, delčnost in pretočne lastnosti. 